Onyshchenko 5., Melnyk 0.

\title{
MODELLING OF CHANGES IN SHIP'S OPERATIONAL CONDITION DURING TRANSPORTATION OF OVERSIZED AND HEAVY CARGO
}

The object of research is the operational condition of the ship and its changes that occur in the process of transportation of oversized and heavy cargo under the influence of multiple accidental events. A significant problem is the negative impact of the system of factors on seaworthiness and technical condition of the ship, the integrity of the cargo. Therefore, ensuring the safety of the ship, its functional reliability as a technical object is among the priorities which are extremely relevant in the process of transportation of oversized and heavy cargo.

In the course of the research the identification of the basic conditions of the surveyed ship in the process of operation was carried out. The ship in the process of transportation is defined as an aggregate of two objects «ship - cargo». The decomposition of the stated condition into two variants «in norm» and «having problems», with three components: «seaworthiness of the ship», «technical condition of the ship», and «cargo and lashing systems». Six main operational conditions of the ship in the process of transportation of oversized and heavy cargo were established. The model of changes in the operational condition of the ship during the transportation of oversized and heavy cargo has been developed. This model enables to establish the relationship between these conditions, which are identified and formalized in the form of a single-ordered Markov process model. The process is considered as a process with a discrete time and the presence of a rotational condition with the absence of the property of ergodicity. Experimental investigations were carried out for various initial conditions and the most probable changes in the operational condition of the ship were determined for a specified number of hourly periods.

The proposed process model enables experimental investigations for various initial conditions and identification of the most probable changes in the ship's operational condition through a specified number of hours. It allows to estimate risks and make decisions on support of ship's operational condition during transportation of oversized and heavy cargo as a theoretical basis.

Keywords: ship's operational condition, transportation of oversized and heavy cargoes, Markov process, control actions.

\section{Introduction}

Improving the safety of ship operation is an essential task that always requires a keen attention. Ship or cargo deterioration due to unacceptable conditions of sufficient ship's stability, failure of hull structural integrity, reliability of ship's equipment and facilities - the whole list of scenarios in which the ship can be involved in the process of operation is inexhaustible. Ship operation safety includes a whole set of measures. The main aspects related to safe operation of modern sea-going ships must properly take into account technical and operational factors that have an indirect impact on the ship's condition in the process of performing the tasks of cargo transportation. The most important are environmental conditions and human factor in decision-making, as an influence of subjective factors on safe operation and technical safety of ships. Therefore, ensuring safety of the ship, its functional reliability as a technical object is among the priorities, which are extremely relevant in the process of transportation of oversized and heavy cargo (OHC).

In solving problems related to the safety of maritime transportation an important role is played by simulation modeling, which enables on the basis of statistical data and expert evaluations to predict the condition of the ship at a certain moment in time.

The issues of probabilistic assessment of conditions of ship's passage between ports were considered in works [1-3]. In particular, the work [3] evaluated the efficiency of ship operation considering the negative impact of various factors. Changes in the ship's condition can be described by means of the Markov process apparatus.

In order to solve such problems certain theoretical and practical experience has been accumulated using the apparatus of Markov processes theory, including transport sphere [4], i. e. stochastic model, which has Markov property a specific type of accidental processes. In particular, on the use of Markov processes:

- the procedure for assessing the accident rate of ships when entering and leaving the port has been developed $[5,6]$

- the process of identification of the fishing ship operation conditions is carried out [7];

- other tasks in the field of maritime transport, which are related to safety [8-10]. 
However, it is necessary to note that the results of the conducted researches do not fully reflect the specifics of the operation of maritime transport means and provide tools for ensuring safety during transportation of OHC. Therefore, this issues are of particular interest.

Thus, the object of research is the operational condition of the ship and its changes that occur in the process of transportation of oversized and heavy cargo under the influence of multiple accidental events.

The aim of the research is to simulate changes in the ship's operational condition during transportation of oversized and heavy cargo.

\section{Methods of research}

Ship's condition in the process of transportation can be represented as the condition of the two objects «ship cargo». The resultant operational condition of the ship during transportation is formed considering various events related directly to the ship (e. g. failure of technical systems) or the cargo (its shifting).

Transition of the «ship - cargo» system from one condition to another during the voyage is influenced by a number of accidental factors such as: weather conditions, «human factor», ship's condition at the beginning of the voyage, the quality and quantity of lashing materials, etc. Therefore, there are grounds and necessary conditions for identification of the process of change in the operational condition of the ship when transporting $\mathrm{OHC}$ as a Markov process.

To identify the basic conditions of the studied object «ship - cargo» it is suggested to decompose the above condition into two variants («normal», «problems») by three components: «seaworthiness of the ship», «technical condition of the ship», and «cargo and lashing systems». This approach is determined, first of all, by the specifics of ship operation when transporting OHC, which is reflected, for example, in the peculiarities of cargo stowage and lashing on board. This, accordingly, can lead to certain violations both during the process of loading on the board, and violation of the «integrity» of the system «ship - cargo» in the process of transportation. Positive («in norm» - 1) and negative («having problems»-0) estimation of each component forms the following classification of the main variants of ship's condition (Table 1).

Two theoretically feasible variants are: the cargo is in good technical and seaworthy condition; the loss of seaworthiness and the unsuitable condition of the cargo in normal technical condition does not have any practical sense.

The next stage of the research is to determine the type of the Markov process. Since the number of the considered conditions is a countable set, a discrete random process takes place. Since the status of the ship is performed at certain moments of time, there is a Markov process with a discrete time $t=0,1,2,3, \ldots$. Let's consider the considered Markov's chain to be unidirectional, because the probability of transition from one condition to another does not depend on the time, but depends exclusively on the complex of accidental factors of influence.

A year, a day or even a decade can be a moment of time, but taking into account the specifics of the dynamics of changes in weather conditions and the situation on board the ship, for $t=0,1,2,3, \ldots$ accept the day (24 hrs) within the voyage period.
Table 1

Classification of the main operational conditions of the ship when transporting oversized and heavy cargoes

\begin{tabular}{|c|c|c|c|l|}
\hline $\begin{array}{c}\text { Condi- } \\
\text { tion }\end{array}$ & $\begin{array}{c}\text { Sea- } \\
\text { worthi- } \\
\text { ness }\end{array}$ & $\begin{array}{c}\text { Tech- } \\
\text { nical } \\
\text { condi- } \\
\text { tion }\end{array}$ & $\begin{array}{c}\text { Cargo } \\
\text { and } \\
\text { lashing } \\
\text { systems }\end{array}$ & \multicolumn{1}{|c|}{ Description } \\
\hline $\mathbf{5 1}$ & 1 & 1 & 1 & Normal operating conditions of the ship \\
\hline $\mathbf{5 2}$ & 1 & 1 & 0 & Damage or/and loss of cargo \\
\hline $\mathbf{5 3}$ & 1 & 0 & 0 & $\begin{array}{l}\text { Damage or/and loss of cargo, damage } \\
\text { to ship's structural elements and deck } \\
\text { equipment }\end{array}$ \\
\hline $\mathbf{5 4}$ & 1 & 0 & 1 & $\begin{array}{l}\text { Damage to the ship's structural elements } \\
\text { and deck equipment as a result of shift- } \\
\text { ing of cargo/crushing of lashing systems }\end{array}$ \\
\hline $\mathbf{5 5}$ & 0 & 1 & 1 & $\begin{array}{l}\text { Appearance of a dangerous heel, de- } \\
\text { terioration/loss of ship's stability as } \\
\text { a result of cargo shifting }\end{array}$ \\
\hline $\mathbf{5 6}$ & 0 & 0 & 0 & $\begin{array}{l}\text { Unsatisfactory ship's operational condi- } \\
\text { tions and emergency situation }\end{array}$ \\
\hline
\end{tabular}

The graph of conditions and transitions of the studied object is shown in Fig. 1.

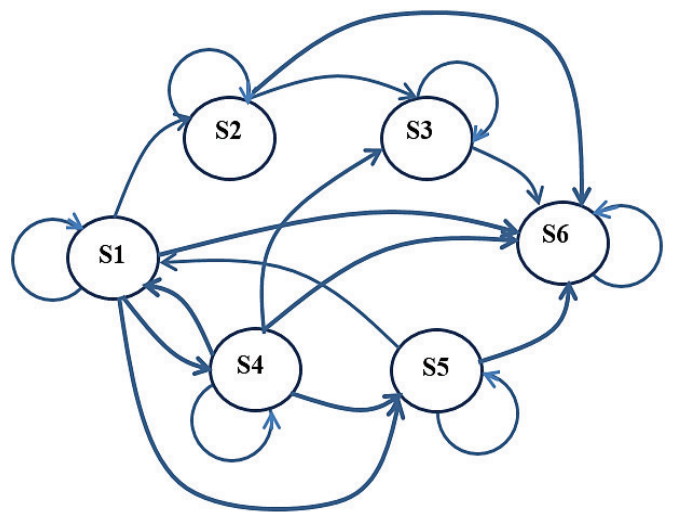

Fig. 1. Transition graph of the ship's operational conditions

It should be noted that the normal operational condition of $\mathbf{S} \mathbf{1}$ is a turning point, since the ship can return to it, for example, as a result of normalization of weather conditions, even with the preceding influence of negative factors.

Matrix of transition probabilities:

$$
P=\left[p_{i j}\right]=\left[\begin{array}{cccccc}
p_{11} & p_{12} & 0 & p_{14} & p_{15} & p_{16} \\
0 & p_{22} & p_{23} & 0 & 0 & p_{26} \\
0 & 0 & p_{33} & 0 & 0 & p_{36} \\
p_{41} & 0 & p_{43} & p_{44} & p_{45} & p_{46} \\
p_{51} & 0 & 0 & 0 & p_{55} & p_{56} \\
0 & 0 & 0 & 0 & 0 & 1
\end{array}\right],
$$

where

$$
0 \leq p_{i j} \leq 1, i=\overline{1,6}, j=\overline{1,6} .
$$

Let's note that the matrix (1) already contains zero values of probabilities for impracticable condition transitions according to the column in Fig. 1. At the same time, the condition $\mathbf{S} 6$ is non-returnable, i. e. the ship does not leave this condition, so the corresponding probability $p_{66}=1$. 
That means that the examined Markov's chain does not have the property of ergodicity.

According to the properties of the Markov process the elements of the matrix satisfy the conditions:

$$
\sum_{j=1}^{6} p_{i j}=1, i=\overline{1,6}
$$

The Markov process requires the initial probabilities to be set $p_{1}(0), p_{2}(0), p_{3}(0), p_{4}(0), p_{5}(0), p_{6}(0)$ location of the «ship - cargo» system at the initial moment of time $t=0$ :

$$
p_{1}(0)+p_{2}(0)+p_{3}(0)+p_{4}(0)+p_{5}(0)+p_{6}(0)=1 \text {. }
$$

That given moment of time $(t=0)$ is the departure of the ship from the loading port. In fact, initial probabilities assess how many accidental factors influence the process of ship loading and the condition of the ship itself before the loading commences. Thus, the initial condition of the system «ship - cargo», which forms the initial operational condition of the ship for the given voyage, $p_{1}(0), p_{2}(0), p_{3}(0), p_{4}(0)$, $p_{5}(0), p_{6}(0)$, is determined on the basis of an analysis of the possible impact of the system of factors for a particular ship. This is done taking into account its characteristics and peculiarities of the previous operation, the cargo, the port of loading (according to expert opinion or statistics).

Since this process has no ergodic character, it does not have a steady mode (condition). Therefore, after a significant interval of time, the probability of the conditions does not follow to the limit values, which do not depend on the initial conditions and the current moment of time. Thus, the Markov process - the system «ship - cargo» in the process of transporting - «starts up» from a certain initial condition. $p_{1}(0), p_{2}(0), p_{3}(0), p_{4}(0), p_{5}(0), p_{6}(0)$, which determines the probability of further ship's position in one or another condition during the voyage.

On the basis of the Kolmogorov-Chepman equation (5) it is possible to determine the probability of operational conditions of the ship at any given moment of time.

$$
p_{j}(k)=\sum_{i=1}^{n} p_{j}(k-1) \cdot p_{i j}, \quad j=\overline{1, n}, \quad k=1,2,3, \ldots
$$

Thus, the dynamics of the operational condition of the ship is studied on the basis of the proposed Markov chain.

\section{Research results and discussion}

Experimental research of the proposed imitation model (condition graph and transition matrix are the ones that create the imitation), which depicts the changes in the ship's operational condition, was carried out using the following output data:

- matrix of transition probabilities:

$$
\begin{aligned}
& P=\left[p_{i j}\right]= \\
& =\left[\begin{array}{cccccc}
0.99 & 0.0092 & 0 & 0.0004 & 0.0003 & 0.0001 \\
0 & 0.7 & 0.27 & 0 & 0 & 0.03 \\
0 & 0 & 0.7 & 0 & 0 & 0.3 \\
0.1 & 0 & 0.2 & 0.5 & 0.1 & 0.1 \\
0.1 & 0 & 0 & 0 & 0.5 & 0.4 \\
0 & 0 & 0 & 0 & 0 & 1
\end{array}\right] ;
\end{aligned}
$$

- at different values of operational conditions of the ship, which are considered at the initial moment of time $t=0$ :

1) $P_{1}(0)=0.99 ; P_{2}(0)=0.01 ; P_{3}(0)=0$;

$P_{4}(0)=0 ; P_{5}(0)=0 ; P_{6}(0)$;

2) $P_{1}(0)=0.95 ; P_{2}(0)=0.05 ; P_{3}(0)=0$;

$P_{4}(0)=0 ; P_{5}(0)=0 ; P_{6}(0)$;

3) $P_{1}(0)=0.90 ; P_{2}(0)=0.10 ; P_{3}(0)=0 ; P_{4}(0)=0$;

$P_{5}(0)=0 ; P_{6}(0)$;

4) $P_{1}(0)=0.85 ; P_{2}(0)=0.15 ; P_{3}(0)=0 ; P_{4}(0)=0$;

$P_{5}(0)=0 ; P_{6}(0)$.

Four variants of the ship's initial operational condition are determined by the specifics of cargo operations and the condition of the ship before the voyage commences. The first option is the most acceptable of those considered, the fourth option sets, in fact, $15 \%$ of the possible losses in the process of loading and not exactly the optimal condition of the ship before the commencement of cargo operations.

Thus, the port, the cargo and the ship determine the probability of operational condition of the ship (the system «ship - cargo»).

For all considered variants of probabilities of ship's condition at the moment of time $t=0$, corresponding calculations were carried out according to formula (5), which allowed to form such regularities (Fig. 2, 3).

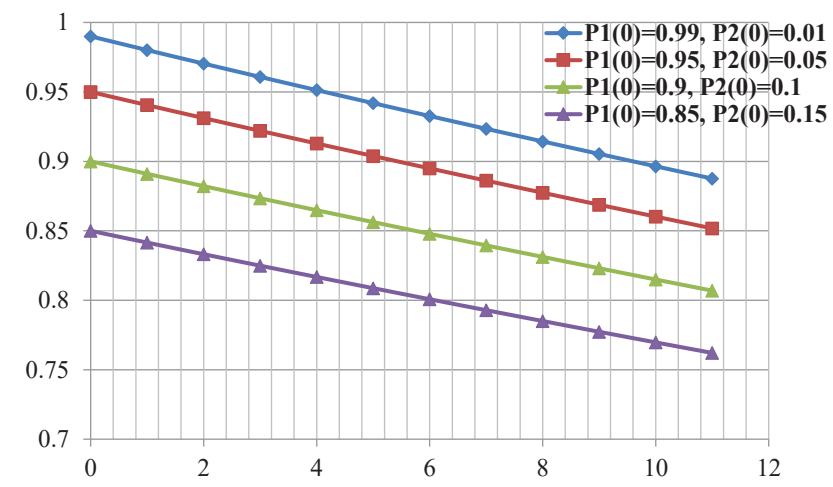

Fig. 2. Dynamics of probability $\mathbf{5 1}$ for different variants of initial probabilities (moment of time $t=0$ )

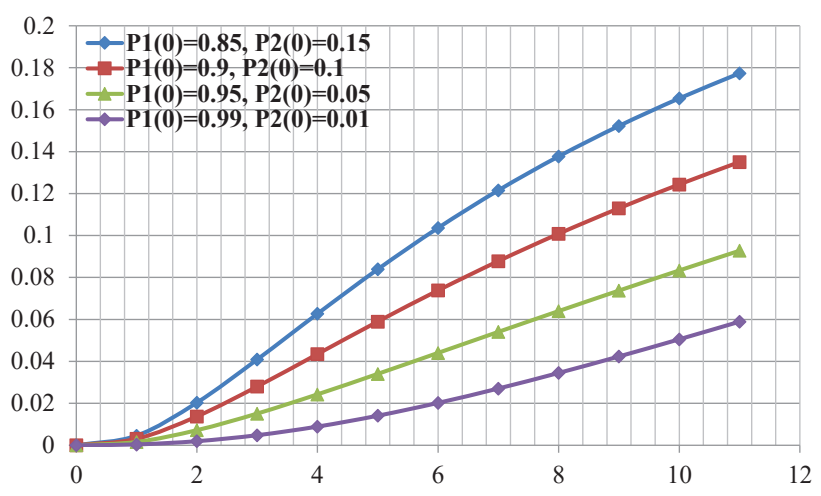

Fig. 3. Dynamics of probability $\mathbf{5 6}$ for different variants of initial probabilities (moment of time $t=0$ ) 
Fig. 1 demonstrates that the probability of ship's condition $\mathbf{S} 1$ decreases practically linearly from any starting point, and, for example, for the 4th variant of starting conditions:

$$
\begin{aligned}
& P_{1}(0)=0.85 ; P_{2}(0)=0.15 ; P_{3}(0)=0 ; \\
& P_{4}(0)=0 ; P_{5}(0)=0 ; P_{6}(0),
\end{aligned}
$$

at the 11th hour step reaches practically 0.75 . This is explained, first of all, by the specifics of the matrix (6). At the same time, for the first initial condition:

$$
\begin{aligned}
& P_{1}(0)=0.99 ; \quad P_{2}(0)=0.01 ; P_{3}(0)=0 ; \\
& P_{4}(0)=0 ; P_{5}(0)=0 ; P_{6}(0),
\end{aligned}
$$

at the same 11th hour step, the probability of $\mathrm{S} 1$ is practically 0.9 .

Fig. 2 shows the dynamics of the probability of the highest condition of the ship S6. On the 11th hour step section for the first initial condition $P_{1}(0)=0.99 ; P_{2}(0)=0.01$; $P_{3}(0)=0 ; P_{4}(0)=0 ; P_{5}(0)=0 ; P_{6}(0)$ probability of this condition is close to 0.06 , which can be assumed as an acceptable situation. For the fourth initial condition $P_{1}(0)=0.85$; $P_{2}(0)=0.15 ; P_{3}(0)=0 ; P_{4}(0)=0 ; P_{5}(0)=0 ; P_{6}(0)$, probability of the $\mathbf{S 6}$ condition is close to 0.18 , which cannot be considered acceptable. At the next stage of experimental studies, the transition probability matrix was changed to a more «optimistic» variant:

$$
\begin{aligned}
& P=\left[p_{i j}\right]= \\
& =\left[\begin{array}{cccccc}
0.99 & 0.00925 & 0 & 0.00045 & 0.0003 & 0.00001 \\
0 & 0.85 & 0.149 & 0 & 0 & 0.001 \\
0 & 0 & 0.95 & 0 & 0 & 0.05 \\
0.1 & 0 & 0.17 & 0.7 & 0.02 & 0.01 \\
0.1 & 0 & 0 & 0 & 0.6 & 0.3 \\
0 & 0 & 0 & 0 & 0 & 1
\end{array}\right] .
\end{aligned}
$$

In this matrix, the probability of transition to $\mathbf{S} \mathbf{6}$ is significantly lower than for the previous variant. In addition, the probability of ship's presence in conditions $\mathbf{S 2}$, S3, S5 has increased. Thus, more probability is ensured for a certain fixed condition of the ship.

The corresponding graphs of variation of probabilities of ship's condition $\mathbf{S 1}, \mathbf{S 6}$ are shown in Fig. 4, 5. It should be noted that the dynamics of probabilities of $\mathbf{S} \mathbf{1}$ remained the same, which is explained by the absence of changes in the matrix of transient probabilities for this condition. However, the changes in (8) affected all other conditions of the ship.

The dynamics for $\mathbf{S 6}$ is more «optimistic» and, in particular, the probability of the $\mathbf{S} 6$ condition for the first variant of the initial probabilities at the 11 th hour step: $P_{1}(0)=0.99 ; P_{2}(0)=0.01 ; P_{3}(0)=0 ; P_{4}(0)=0 ; P_{5}(0)=0 ; P_{6}(0)$ makes a bit more 0.01 (as compared to 0.06 in the previous situation). Also on the 11th hour step the probability of the condition $\mathbf{S} \mathbf{6}$ for the fourth variant of the initial probabilities: $P_{1}(0)=0.85 ; P_{2}(0)=0.15 ; P_{3}(0)=0 ; P_{4}(0)=0$; $P_{5}(0)=0 ; P_{6}(0)$ is slightly less than 0.04 (compared to 0.18 in the previous situation).

Thus, an imitation model of changes in the ship's operational condition in the process of $\mathrm{OHC}$ transportation has been developed, which enables experimental research for different initial conditions and determining the most probable changes in the ship's operational condition.

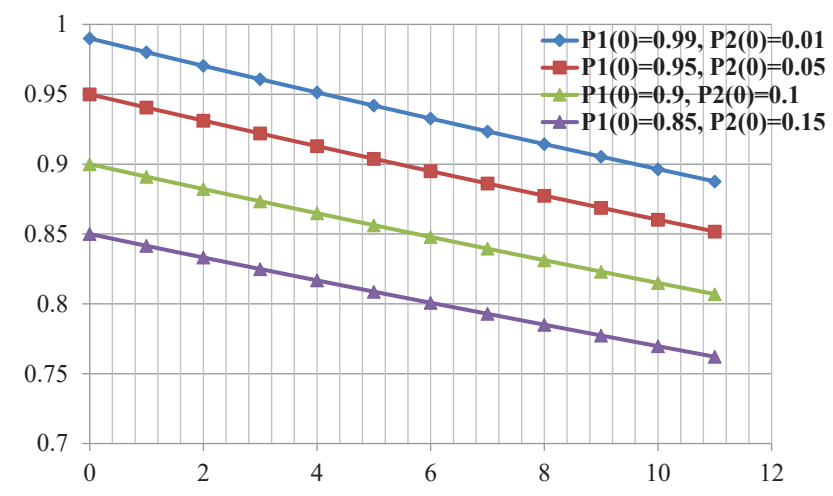

Fig. 4. Dynamics of the probability of the condition $\mathbf{5 1}$ for different variants of initial probabilities (moment of time $t=0$ )

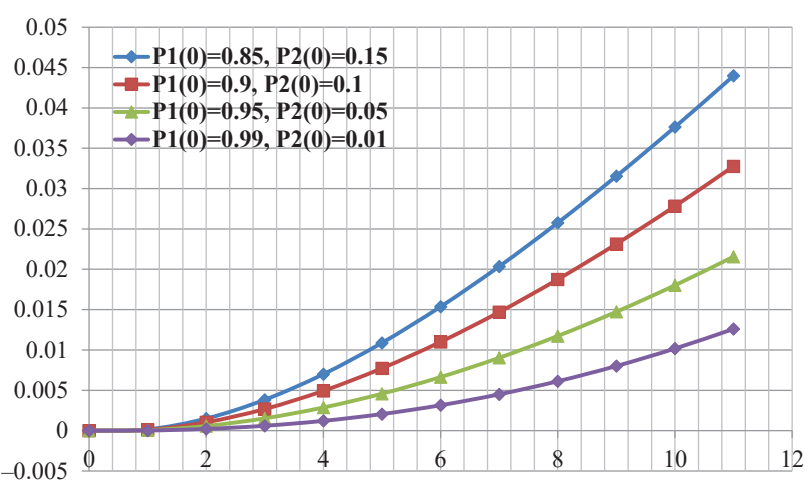

Fig. 5. Dynamics of probabilities of the condition $\mathbf{5 6}$ for different variants of initial probabilities (moment of time $t=0$ )

Experimental studies demonstrate the possibilities of practical use of the developed model of the Markov process. This model describes the change in the ship's operational condition in the process of OHC transportation. Experimental research allows to make a conclusion about the adequacy of the proposed approach to the real processes of ship operation and validity of the results obtained on its basis.

So, depending on a number of factors, initial probabilities for six identified ship's operational conditions are formed. The relationship between these conditions is identified and formalized in the form of a single-order Markov process model with a discrete time, the presence of a non-reversible condition S6 (i. e. with the absence of the property of ergodicity).

\section{Conclusions}

The main operational changes in the operational condition of the ship during the transportation of oversized and heavy cargo are identified. The simulation model of changes in the ship's operational condition during OHC transportation has been developed. The relationship between these conditions is defined and formalized in the form of a single-order Markov process model with a discrete time, the presence of a non-reversible condition (i. e. with the absence of the property of ergodicity). The proposed process model enables experimental studies for various initial conditions and identification of the most probable changes in the ship's operational condition through a given number of hour-step intervals. In its turn, it makes it possible 
to assess the risks and make decisions on the ship's operational condition in the process of $\mathrm{OHC}$ transportation as a theoretical basis. Experimental studies for various initial conditions were conducted and the most probable changes in the ship's operational condition were determined for a given number of hour steps.

\section{References}

1. Onyshchenko, S., Vyshnevska, O. (2016). Assessment method for deviation of the work's results for vessel under the influence of risk factors. Bulletin of NTU «KhPI». Series: Mechanicaltechnological systems and complexes, 7, (1179), 25-32.

2. Onyshchenko, S. P., Koskina, Y. A. (2019). Estimation of the time of the vessel's arrival at port. Science and Transport Progress. Bulletin of Dnipropetrousk National University of Railway Transport, 1 (79), 39-50. doi: http://doi.org/10.15802/stp2019/158478

3. Schneider, T., Armingaud, F., Tabarre, M. (1999). Statistical Analysis of Accident Data Associated with Sea Transport (Data from 1994-1997). Rep. CEPN-IPSN, NTE/99/02. Institut de Protection et de Sûreté Nucléaire. Fontenay-aux-Roses.

4. Ovchinnikova, N. I., Kosareva, A. V., Bonnet, V. V., Eltochkina, E. V. (2019). A simple semi-Markov model of functioning of agricultural cleaning and transport system. Journal of Physics: Conference Series, 1333, 032061. doi: http://doi.org/10.1088/1742$6596 / 1333 / 3 / 032061$

5. Girtler, J. (2013). Application of theory of semi-Markov processes to determining distribution of probabilistic process of marine accidents resulting from collision of ships. Polish Maritime Research, 21 (1), 9-13. doi: http://doi.org/10.2478/pomr-2014-0002

6. Guze, S., Smolarek, L. (2012). Semi-Markov Approach to the Shipping Safety Modelling. Archives of Transport, 23 (4), 475-488. doi: http://doi.org/10.2478/v10174-011-0032-7

7. Peel, D., Good, N. M. (2011). A hidden Markov model approach for determining vessel activity from vessel monitoring system data. Canadian Journal of Fisheries and Aquatic Sciences, 68 (7), 1252-1264. doi: http://doi.org/10.1139/f2011-055

8. Guze, S., Kołowrocki, K. (2017). Safety modeling of port, shipping and ship traffic and port operation information critical infrastructure join network related to its operation process. Safety and Reliability - Theory and Applications. doi: http:// doi.org/10.1201/9781315210469-98

9. Mageirou, E. (2012). Stochastic Optimal Positioning of Tramp Vessels: A Markovian Approach.

10. Korolyuk, V. S., Brodi, S. M., Turbin, A. F. (1975). Semi-markov processes and their applications. Journal of Soviet Mathematics, 4 (3), 244-280. doi: http://doi.org/10.1007/bf01097184

Onyshchenko Svitlana, Doctor of Economic Sciences, Professor, Director, Educational and Scientific Institute of Marine Business, Odessa National Maritime University, Odessa, Ukraine, e-mail: onyshenko@gmail.com,ORCID:http://orcid.org/0000-0002-7528-4939

Melnyk Oleksiy, Senior Lecturer, Department of Navigation and Maritime Security, Odessa National Maritime University, Odessa Ukraine, e-mail: m.onmu@ukr.net, ORCID: http://orcid.org/00000001-9228-8459 